\title{
Congenital and developmental cataract surgery with under corrected Intraocular lens (IOL) power implantation targeting emmetropia at 8 years of age and post-operative refractive status
}

\author{
Kabindra Bajracharya ${ }^{1}$, Anjita Hirachan ${ }^{2}$, Kriti Joshi ${ }^{3}$, Bimala Bajracharya ${ }^{4}$ \\ ${ }^{1}$ Associate Professor and Consultant Pediatric Ophthalmologist, ${ }^{2}$ Assistant Professor and Consultant Pediatric \\ Ophthalmologist, ${ }^{3}$ Fellow Pediatric Ophthalmology and Strabismus, ${ }^{4}$ Nursing Consultant, Lumbini Eye Institute and \\ Research Center, Bhairahawa, Nepal
}

\section{A B S T R A C T}

Background: In congenital and developmental cataract primary undercorrection of intraocular lens (IOL) power is a common practice. However, long-term refractive status of these children is largely unknown. Aims and Objective: To analyse refractive status after cataract surgery with undercorrected IOL power implantation in congenital and developmental cataract. Materials and Methods: This study was descriptive, retrospective conducted for three years from $1^{\text {st }}$ January 2013 to $31^{\text {st }}$ December 2015 . The children ( $>6$ months to $<=7$ years of age) who underwent cataract surgery for congenital and developmental cataract with a primary IOL implantation and had reached the age of 8 years were studied. The data were collected in terms of demography, axial length, biometry, IOL implanted, hyperopic correction and postoperative refractive status at 8 years. Results: Total numbers of children operated were 181 with total eyes 288. Unilateral cases were $74(40.88 \%)$ and bilateral $107(59.12 \%)$. Male were $121(66.85 \%)$ and female were $60(33.15 \%)$ with male is to female ratio of $2: 1$. Right eye was involved in $152(52.8 \%)$ and left eye $136(47.2 \%)$. The mean axial length at the age of one year was $20.75 \mathrm{~mm}$, and gradually increased as age increased which was $22.47 \mathrm{~mm}$ at 6 years. The mean biometry was 27.9 diopter (D) at the age of one year which gradually decreased as age increased. Of the total 288 congenital cataract operated, complete follow-up documents were available for $77(26.74 \%)$ eyes up to 8 years which showed emmetropia achieved in $25.97 \%$, myopia in $28.57 \%$ and hypermetropia in $45.45 \%$. Conclusion: Primary IOL implantation with hyperopic correction is accepted practice in congenital and developmental cataract. Emmetropia can be achieved however some hyperopic or myopic refractive status at the age of 8 years is not a surprise. Myopic shift continues as the age increases. Parent awareness for early detection and surgery, optical correction and regular follow-up are essential for good outcome.

Key words: Congenital and developmental cataract surgery; hyperopic correction; refractive status at 8 years

\section{INTRODUCTION}

Congenital cataract is the most common cause of treatable childhood blindness which is responsible for $5-20 \%$ of the causes ${ }^{1}$. Surgery for congenital visually significant
Access this article online

Website:

http://nepjol.info/index.php/AJMS DOI: 10.3126/ajms.v12i9.36890

E-ISSN: 2091-0576

P-ISSN: 2467-9100

Copyright (c) 2021 Asian Journal of Medical Sciences

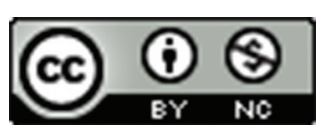

This work is licensed under a Creative Commons Attribution-NonCommercial 4.0 International License. 
Primary IOL implantation in pediatric cataract has been the choice of surgical procedure. Initial undercorrection of IOL power is a common practice. The age at which IOL needs to be implanted is still debatable when it comes to infants and toddlers. In Nepal, National Pediatric Cataract Workshop in 2015 has developed protocol for IOL implantation after 6 months of age. ${ }^{2}$ As the incidence of adverse events are high in the children less than 6 months, surgeon should be cautious.

There are various studies suggesting different diopter deduction of calculated biometric power according to the age of the child and axial length of the eyes. Dahan's formula and "Enyedi's rule of seven" are commonly used for undercorrection. ${ }^{3}$ The other option is full correction at the primary surgery and IOL exchange in later dates keeping in consideration for prevention of amblyopia. If undercorrected primary IOL is implanted, second surgery for IOL exchange doesn't require but long-term refractive status of these children is largely unknown.

The objective of this study was to analyse refractive status after cataract surgery with undercorrected IOL power implantation in congenital and developmental cataract.

\section{MATERIALS AND METHODS}

This study was descriptive, retrospective conducted for three years from $1^{\text {st }}$ January 2013 to $31^{\text {st }}$ December 2015, in Pediatric Ophthalmology and Strabismus department of Lumbini Eye Institute and Research Center. The approval was taken from Institutional Review Committee.

The inclusion criteria were children with congenital and developmental cataract $(>6$ months to $<=7$ years of age) with primary IOL implantation and had reached the age of 8 years. The exclusion criteria were traumatic cataract, complicated cataract, syndromic cataract, microphthalmic cataract. The data were collected in terms of demography, axial length, biometry, IOL implanted, hyperopic correction and postoperative refractive status at 8 years.

The data were entered in SPSS version 20 and variables were analysed as frequency and percentage.

\section{RESULTS}

Total number of children operated for congenital and developmental cataract were 181 with total eyes 288. Unilateral cases were $74(40.88 \%)$ and bilateral $107(59.12 \%)$. Male were $121(66.85 \%)$ and female were $60(33.15 \%)$ with male is to female ratio of $2: 1$. Right eye was involved in $152(52.8 \%)$ and left eye $136(47.2 \%)$.
The age of congenital cataract surgery performed showed late presentation (57.3\% after 4 years of age) (Table 1$)$.

The mean axial length at the age of one year was $20.75 \mathrm{~mm}$, and gradually increased as age increased which was at 6 years $22.47 \mathrm{~mm}$ and at 7 years $21.93 \mathrm{~mm}$ (Table 2).

The Intraocular lens powers (biometry) of various ages were as shown in the Table 3 . The mean biometry was 27.9 diopter (D) at the age of one year which gradually decreased as age increased.

The postoperative hyperopic correction needed after undercorrected IOL implantation were as shown in Table 4.

Of the total 288 congenital cataract operated, complete follow-up documents were available for 77 (26.74\%) eyes up to 8 years which showed emmetropia achieved in 20

\begin{tabular}{lcc}
$\begin{array}{l}\text { Table 1: Age of congenital cataract surgery } \\
\text { performed }\end{array}$ \\
\hline Age (years) & Number & Percent (\%) \\
\hline 1 & 16 & 5.6 \\
2 & 34 & 11.8 \\
3 & 46 & 16 \\
4 & 27 & 9.4 \\
5 & 53 & 18.4 \\
6 & 67 & 23.3 \\
7 & 45 & 15.6 \\
Total & 288 & 100 \\
\hline
\end{tabular}

\begin{tabular}{|c|c|c|c|c|c|}
\hline \multirow{2}{*}{$\begin{array}{l}\text { Age } \\
\text { (years) }\end{array}$} & \multirow[t]{2}{*}{ Number } & \multicolumn{4}{|c|}{ Axial length (mm) } \\
\hline & & Minimum & Maximum & Mean & SD \\
\hline 1 & 16 & 18.54 & 22.13 & 20.75 & 1.09 \\
\hline 2 & 34 & 18.61 & 24.33 & 21.32 & 1.29 \\
\hline 3 & 46 & 19.15 & 24.22 & 21.95 & 1.18 \\
\hline 4 & 27 & 19.06 & 24.51 & 21.62 & 1.40 \\
\hline 5 & 53 & 19.65 & 27.10 & 22.38 & 1.76 \\
\hline 6 & 67 & 19.53 & 25.45 & 22.47 & 1.55 \\
\hline 7 & 45 & 18.27 & 25.94 & 21.93 & 1.91 \\
\hline Total & 288 & & & & \\
\hline
\end{tabular}

\begin{tabular}{lccccc}
\multicolumn{3}{l}{ Table 3: Biometry of eyes at various ages } \\
\hline $\begin{array}{l}\text { Age } \\
\text { (years) }\end{array}$ & Number & \multicolumn{4}{c}{ Biometry (diopter) } \\
\cline { 2 - 6 } & & Minimum & Maximum & Mean & SD \\
\hline 1 & 16 & 25 & 34 & 27.91 & 3.02 \\
2 & 34 & 15 & 33 & 26.38 & 3.98 \\
3 & 46 & 12 & 33 & 24.55 & 3.93 \\
4 & 27 & 16 & 35 & 25.11 & 4.63 \\
5 & 53 & 10.5 & 31 & 22.53 & 4.68 \\
6 & 67 & 14 & 33 & 22.75 & 4.83 \\
7 & 45 & 13 & 33.5 & 24.64 & 5.46 \\
Total & 288 & & & & \\
\hline
\end{tabular}


out of 77 (25.97\%), myopia of $<-1 \mathrm{D}$ in $28.57 \%$ and hypermetropia of $>1 \mathrm{D}$ in $45.45 \%$ (Table 5).

The refractive status of congenital cataract operated at various ages and reached 8 years had been shown in Table 6 .

\section{DISCUSSION}

Congenital and developmental cataract in our study was bilateral in $59.12 \%$. It was similar to study by Zhu et al., ${ }^{4}$ (56.3\%), Rahi JS et al., ${ }^{5}(66 \%)$ and Prado RB et al., $(65.9 \%)^{6}$. Male children were commonly affected than female $(66.85 \%)$ in this study similar as in various studies. ${ }^{4-8}$ There was no preference for laterality of eyes and almost equal in either eyes (52.8\% right eye).

The age of congenital cataract surgery performed showed late presentation for surgery (57.3\% after 4 years of age). In various studies performed in Nepal, Shrestha et al., ${ }^{8}$ found the presentation for surgery in children, it was above

\begin{tabular}{lccc}
\multicolumn{4}{l}{$\begin{array}{l}\text { Table 4: } \\
\text { after undean hyperopic correction needed }\end{array}$} \\
$\begin{array}{l}\text { Age } \\
\text { (years) }\end{array}$ & Number & $\begin{array}{c}\text { Targeted } \\
\text { postoperative } \\
\text { refraction (diopter) }\end{array}$ & $\begin{array}{c}\text { Mean hyperopic } \\
\text { correction } \\
\text { needed (diopter) }\end{array}$ \\
\hline 1 & 16 & 3.5 & 3.38 \\
2 & 34 & 3.0 & 3.01 \\
3 & 46 & 2.5 & 2.42 \\
4 & 27 & 2.0 & 1.67 \\
5 & 53 & 1.5 & 1.55 \\
6 & 67 & 1.0 & 1.07 \\
7 & 45 & 0.5 & 0.90 \\
Total & 288 & & \\
\hline
\end{tabular}

\begin{tabular}{llcc}
$\begin{array}{l}\text { Table 5: The type of refractive status at the age } \\
\text { of } 8 \text { years }\end{array}$ & & \\
\hline $\begin{array}{l}\text { Refractive } \\
\text { status at } 8 \text { years }\end{array}$ & $\begin{array}{l}\text { Type of refractive } \\
\text { status at } 8 \text { years }\end{array}$ & Number & $\begin{array}{c}\text { Percent } \\
\text { (\%) }\end{array}$ \\
\hline$<=-1$ & Myopia & 22 & 28.57 \\
$0-1$ & Emmetropia & 20 & 25.97 \\
$>=+1$ & Hypermetropia & 35 & 45.45 \\
Total & & 77 & 100 \\
\hline
\end{tabular}

\begin{tabular}{|c|c|c|}
\hline Age (years) & Number & $\begin{array}{l}\text { Median refractive status (diopter) } \\
\text { at } 8 \text { years }\end{array}$ \\
\hline 1 & NA & NA \\
\hline 2 & 2 & -0.8 \\
\hline 3 & 8 & 2.5 \\
\hline 4 & 6 & 2.0 \\
\hline 5 & 12 & 0.9 \\
\hline 6 & 25 & 0.3 \\
\hline 7 & 24 & 1.0 \\
\hline Total & 77 & 100 \\
\hline
\end{tabular}

8 years in $46 \%$, the mean age at surgery was 6.2 years in study done by Thakur et al., ${ }^{9}$ median age at surgery was 7 years in study done by Wilson et al..$^{10}$ The late presentation for surgery might be due to lack of knowledge among people on needed early management of congenital cataract to prevent amblyopia.

The mean axial length at the age of one year was $20.75 \mathrm{~mm}$, and gradually increased as age increased which was at 6 years $22.47 \mathrm{~mm}$ and at 7 years $21.93 \mathrm{~mm}$. In 5 years (20.75 $\mathrm{mm}$ at 1 year and $22.47 \mathrm{~mm}$ at 6 years), there was $1.72 \mathrm{~mm}$ axial length growth which could change 5 diopter myopic shift. Myopic shift continued as the age increased.

The mean refractive power at 1 years of age was $27.9 \mathrm{D}$ which went on decreasing and at the age of 6-7 years it was 22-23 D. This showed $5 \mathrm{D}$ myopic shift in 5 years' time. The myopic shift was continuing as the age increasing. It was similar to study by Enyedi et al., ${ }^{11}$ and Khokar et al. ${ }^{12}$

The postoperative hyperopic correction needed after undercorrected IOL implantation were accordance to target in this study. After cataract surgery regular follow-up is essential for hyperopic glass prescription in children to give best corrected visual acuity and prevent amblyopia.

Of the total 288 congenital cataract operated, complete follow-up documents were available for 77 (26.74\%) eyes up to 8 years. The possible cause for poor compliance might be due to lack of knowledge among parents, poverty and long travel distance needed for consultation. Among follow-up completed children, emmetropia was achieved in $25.97 \%$. Hyperopia persisted in $45 \%$ and myopia in remaining children similar to study by Sachdeva B et al. ${ }^{13}$ After the age of 8 years some myopic shift is expected till adulthood. For hyperopic patient this will improve towards emmetropia but for myopic patients further amount of myopia will increases.

The IOL implantation in pediatric population, if performed taking in account of age, different study formulas, can give emmetropic outcome but refractive surprise can occur. This study could document the average axial length and refractive power at different ages in Nepalese children, this could be the first of this kind of study in Nepal up to our knowledge on the basis of available literature. And comparing it to other studies was limited. This study has some limitations. It was retrospective study and the follow up compliance was not good as seen in the record. There were only one-fourth follow-up completed cases and the sample was less for different ages. It suggests need of one further prospective study with good follow-up. The study has to be of the long period (at least 8 years for below one year operated case). 


\section{CONCLUSION}

Primary IOL implantation with hyperopic correction is accepted practice in congenital and developmental cataract. Emmetropia can be achieved however some hyperopic or myopic refractive status at 8 years of old is not a surprise. Myopic shift continues as the age increases. Parent awareness for early detection and surgery, optical correction and regular follow up are essential for good outcome.

\section{ACKNOWLEDGEMENT}

The author like to thank Dr Amita Pradhan for doing statistical analysis of the data of this study.

\section{REFERENCES}

1. Sheeladevi S, Lawrenson JG, Fielder AR and Suttle CM. Global prevalence of childhood cataract: a systematic review. Eye (Lond). 2016; 30(9): 1160-1169.

https://doi.org/10.1038/eye.2016.156

2. National Paediatric Cataract Surgery Workshop at SCEH, Lahan. Guidelines for Paediatric Cataract Surgery. 2015. www. nos.com.np/Image/Documents/Pediatric\%20Cataract\%20 Guidelines-2015.pdf. Accessed on 2 May 2021.

3. Sachdeva V, Katukuri S and Kekunnaya R. Validation of Enyedi's rule for undercorrection of intraocular lens (IOL) power in children. JAAPOS. 2016; 20(4): e42.

https://doi.org/10.1016/j.jaapos.2016.07.160

4. Zhu X, Du Y, He W, Sun T, Zhang Y, Chang R, et al. Clinical Features of Congenital and Developmental Cataract in East China: A Five-year Retrospective Review. Sci Rep. 2017; 7(4254)

https://doi.org/10.1038/s41598-017-04332-1

5. Rahi JS, Dezateux C and the British Congenital Cataract Interest
Group. Congenital and Infantile Cataract in the United Kingdom: Underlying or Associated Factors. Invest Ophthalmic Vis Sci. 2000; 41(8): 2108-2114. https://iovs.arvojournals.org/article. aspx?articleid=2123480. Accessed on 4 May 2021.

6. Prado RB, Silva VF, Schellini SA and Rodrigues ACL. Congenital and developmental cataract: axial length and keratometry study in Brazilian children. Arq Bras Oftalmol 2016; 79(1). https://doi.org/10.5935/0004-2749.20160007

7. Khanna RC, Foster A, Krishnaiah S, Mehta MK, Gogate and Parikshit M. Visual outcomes of bilateral congenital and developmental cataracts in young children in south India and causes of poor outcome. Indian J Ophthalmol. 2013; 61(2): 65-70. https://doi.org/10.4103/0301-4738.107194

8. Shrestha $U$ and Shrestha M. Clinical Profile of Paediatric Cataract and Surgery in a Tertiary Eye Care Centre, Nepal. Journal of Nepal Paediatric Society. 2012; 32(1): 14-18. https://doi.org/10.3126/jnps.v32i1.5378

9. Thakur J, Reddy H, Wilson ME, Paudyal G, Gurung R, Thapa S, et al. Pediatric cataract surgery in Nepal. J Cataract Refract Surg. 2004; 30(8): 1629-1635. https://doi.org/10.1016/j.jcrs.2003.12.047

10. Wilson M, Edward, Hennig A, Trivedi RH, Thomas BJ and Singh SK. Clinical Characteristics and Early Postoperative Outcomes of Pediatric Cataract Surgery with IOL Implantation from Lahan, Nepal. Journal of Pediatric Ophthalmology and Strabismus. 2010; 48(5). https://doi.org/10.3928/01913913-20100920-03

11. Enyedi LB, Peterseim MW, Freedman SF and Buckley EG. Refractive changes after pediatric intraocular lens implantation. Am J Ophthalmol. 1998; 126(6): 772-781. https://doi.org/10.1016/S0002-9394(98)00247-5

12. Khokhar SK, Tomar A, Pillay G and Agarwal E. Biometric changes in Indian pediatric cataract and postoperative refractive status. Indian J Ophthalmol. 2019; 67(7): 1068-1072. https://doi.org/10.4103/ijo.IJO_1327_18

13. Sachdeva V, Katukuri S, Kekunnaya R, Fernandes M and Ali MH. Validation of Guidelines for Undercorrection of Intraocular Lens Power in Children. Am J Ophthalmol. 2017; 174: 17-22. https://doi.org/10.1016/j.ajo.2016.10.017

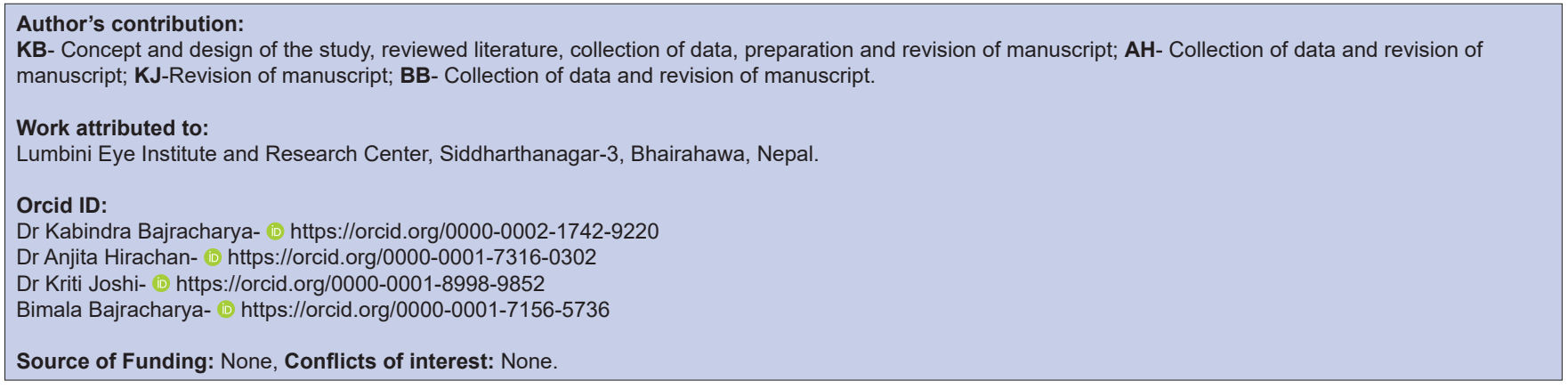

